Hans Lüttger

Vorträge und Abhandlungen 



\title{
Hans Lüttger
}

\section{Vorträge und Abhandlungen}

Ausgewählte Beiträge zum Strafrecht, zur Strafrechtsreform und zum Strafverfahrensrecht aus den Jahren 1950-1985

Mit einem Geleitwort von Hans-Heinrich Jescheck

\author{
Herausgegeben \\ von \\ Theo Vogler
}

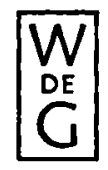

1986

Walter de Gruyter $\cdot$ Berlin $\cdot$ New York 


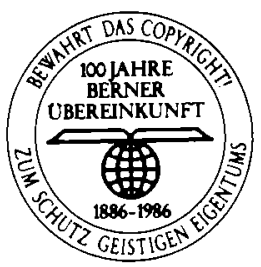

Gedruckt auf säurefreiem Papier

(alterungsbeständig - pH 7, neutral)

CIP-Kurztitelaufnabme der Deutschen Bibliothek

\section{Lüttger, Hans:}

Vorträge und Abhandlungen :

ausgew. Beitr. zum Strafrecht, zur

Strafrechtsreform und zum Strafverfahrensrecht aus d. Jahren 1950-1985/ Hans Lüttger.

Mit e. Geleitw. von Hans-Heinrich Jescheck.

Hrsg. von Theo Vogler. - Berlin ; New York : de Gruyter, 1986.

ISBN 3-11-010714-7

NE: Lüttger, Hans [Sammlung]

(C)

Copyright 1986 by Walter de Gruyter \& Co., 1000 Berlin 30.

Alle Rechte, insbesondere das Recht der Vervielfältigung und Verbreitung sowie der Übersetzung vorbehalten. Kein Teil des Werkes darf in irgendeiner Form (durch Fotokopie, Mikrofilm oder ein anderes Verfahren) ohne schriftliche Genehmigung des Verlages reproduziert oder unter Verwendung elektronischer Systeme verarbeitet, vervielfältigt oder verbreitet werden.

Printed in Germany

Satz und Druck: Saladruck, 1000 Berlin 36

Buchbindearbeiten: Lüderitz \& Bauer, Buchgewerbe GmbH, 1000 Berlin 61 